\title{
Futbolculara Uygulanan Core Egzersizlerinin Bazı Motorik Özellikler Üzerine Etkisi
}

\author{
Rüçhan İRi ${ }^{1}(\mathbb{D}$ \\ Burak ÖZTEKIN² \\ ${ }^{1}$ Niğde Ömer Halisdemir Üniversitesi, Spor Bilimleri Fakültesi, NİĞDE \\ ${ }^{2}$ Niğde Gençlik ve Spor İl Müdürlüğü, $N \dot{I} \breve{G} D E$
} Emrah ŞENGÜR ${ }^{1^{*}}$

\section{DOI: 10.31680/gaunjss.974644}

Orijinal Makale / Original Article Gelis Tarihi / Received: 26.07.2021

\section{Öz}

Çalışmanın amacı futbolculara uygulanan core egzersizlerinin bazı motorik özellikler üzerine etkisinin incelenmesidir. Çalışmaya amatör futbol liginde oynayan 18-25 yaş arası 30 futbolcu gönüllü olarak katılmıştır. Futbolcuların Body Mass Index (BMI), Vücut Yağ Yüzdesi (VYY), sürat, dikey sıçrama, anaerobik güç ve aerobik performansları ölçülmüştür. Kontrol ve deney gruplarının ön test, son test ölçümleri arasındaki farklılığın belirlenmesinde Wilcoxon İşaretli Sıralar testi, ön test ve son test ölçümlerinin gruplar (kontrol-deney) arasındaki farklılığın belirlenmesinde Mann-Whitney $U$ testi analizi kullanılmıştır. Kontrol grubunun ön test son test sonuçlarının karşılaştırılmasında Cooper testi ve VYY değişkenlerinde fark olduğu tespit edilmiştir. Deney grubunun ön test son test karşılaştırılmasında Cooper testi, $20 \mathrm{~m}$ sprint, dikey sıçrama, çeviklik, VYY ve anaerobik güç değişkenlerinde anlamlı fark tespit edilmiştir. Kontrol ve deney gruplarının ön test sonuçlarının karşılaştırılmasında dikey sıçrama ve anaerobik güç değişkenlerinde fark olduğu farkın deney grubu lehine olduğu tespit edilmiştir. Kontrol ve deney gruplarının son test sonuçlarının karşılaştırılmasında dikey sıçrama, anaerobik güç ve çeviklik değişkenlerinde gruplar arası karşıllaştırılmasında fark olduğu, farkın deney grubu lehine olduğu tespit edilmiştir. Sonuç olarak, takım içerisinde kendi antrenman metotlarıyla yüklenmeler yapan futbolculara farklı egzersizler uygulandığında performans gelişiminin olumlu şekilde olacağı tespit edilmiştir. Belirli bir amaç doğrultusunda futbolcuların performansını artırmak amacıyla yapılacak periyotlamalarda core egzersizlerinin kullanılması önerilmektedir.

Anahtar Kelimeler: Futbolcular, core egzersizleri, çeviklik, sürat, dikey sıçrama

\section{The Effect of Core Exercises Applied to Football Players on Some Motoric}

\section{Features}

\begin{abstract}
The aim of the study was to examine the effect of core exercises applied to football players on some motoric features. 30 football players between the ages of 18-25, playing in the amateur football league, participated in the study voluntarily. BMI, body fat percentages, sprint, vertical jump, anaerobic power and aerobic performance of the football players were measured. Wilcoxon Signed Rank test was used to determine the difference between the pre-test and post-test measurements of the control and experimental groups, and the Mann-Whitney $U$ test was used to determine the difference between the pre-test and post-test measurements (control-experiment) between the groups. When comparing the pre-test and post-test results of the control group, it was determined that there was a difference in the Cooper and VYY variables. In the pre-test post-test comparison of the experimental group, a significant difference was found in the variables of Cooper, $20 \mathrm{~m}$ sprint, vertical jump, agility, VYY and anaerobic power. In the comparison of the pre-test results of the control and experimental groups, it was determined that there was a difference in the vertical jump and anaerobic power variables, and the difference was in favor of the experimental group. In the comparison of the post-test results of the control and experimental groups, it was determined that there was a difference in the vertical jump, anaerobic power and agility variables between the groups, and the difference was in favor of the experimental group. As a result, it was determined that the performance improvement will be positive when different exercises are applied to the football players who load with their own training methods in the team. In order to increase the performance of football players for a specific purpose, it is recommended to use core exercises in the periodizations.
\end{abstract}

Keywords: Football players, core exercise, agility, sprint, vertical jump 


\section{Giriş}

Futbol son yıllarda, motorik özellikler, kondisyonel, psikolojik, teknik taktik becerilerin uygulanması yönünden en popüler spor dalıdır. Bunun yanında takım birlikteliğinin kurulmasıyla ve doğru yapılan yüklenmelerle futbolcuların motorik özelliklerinin gelişimi de ön plana çıkmaktadır (Mills, 2016; Meckel, Machnai ve Eliakim, 2009). Özellikle son zamanlarda motorik özelliklerin geliştirilmesi ve korunmasına yönelik olarak core egzersizleri kullanılmaya başlanmıştır.

Core egzersizleri, atletik gelişim ve teknik taktik gibi olguların uygulanmasını kolaylaştıran, omurga, karın, bel ve kalça hareketlerini kontrol ve stabilize eden kasların antrene edilmesine yönelik egzersizleri içeren çalışmalardır. Egzersizler ile geliştirilen core bölge kasları, üst ve alt uzuvlar arasında köprü görevi görmesiyle beraber hareket sırasında oluşturulan kinetik gücün üretilmesine ve gücün bacaktan gövdeye ya da gövdeden bacağa verimli bir şekilde aktarılmasında koordineli olarak çalışmaktadır (Egesoy, Alptekin ve Yapıcı, 2018; Yılmaz, 2021). Core bölgesini kuvvetlendirmenin, sportif performansın geliştirilmesinde katkısı olduğu bilinmektedir (Gönener ve ark., 2017). Özellikle futbolcular üzerine yapılan core egzersizleri incelendiğinde, uygulanan hareketler sonucunda kas hipertrofisinin oluşmasıyla artan kuvvet miktarının denge, yatay sıçrama, aerobik ve anaerobik performans üzerinde etkili olduğu rapor edilmiştir (Aslan ve ark., 2018; Sun ve ark., 2016; Dikici, 2018; Afyon, 2014).

Kuvvetlendirilmiş core bölgesi hem sporcuya daha fazla yüklenme imkanı verirken, hem de sporcuların teknik hareketleri en verimli şekilde uygulamasını sağlayacaktır (Şatıroğlu, Arslan ve Atak, 2013). Bu sebeple core egzersiz programları dizayn edilirken, kuvvet ve güç gelişimlerinde sistematik ilerleme kaydettirecek hareketlere yer verilmeli, stabilizasyon, bedensel hareket ve konum duyusunu (proprioception) geliştirmeye yönelik olmalıdır (Stephenson, 2004: Jones, 2013). Çeşitli branşlarda sporcuların temel motorik özelliklerini geliştirmek amacıyla belirli süre içerisinde core egzersizleri uygulanmaktadır. Bu bağlamda bu çalışmanın amacı core egzersizlerin futbolcuların motorik özellikleri üzerine etkisinin incelemektir.

\section{Yöntem}

\section{Katılımcılar}

Araştırmaya Niğde Belediyespor Futbol Kulübü'nde antrenman yapan 18-25 yaş arası en az 30 (15 kontrol, 15 deney) futbolcu gönüllü olarak katılmıştır. Gruplar belirlenirken mevkilerdeki futbolcu sayısına göre eşit dağılım olacak şekilde rastgele 
gruplama yapılmıştır. Çalışmada Eşitlenmemiş Kontrol Gruplu Model kullanılmıştır. Çalışmanın örneklem grubunu Niğde Belediyespor Futbol Kulübünde antrenman yapan 18-25 yaş arası 30 kişi oluştururken, evrenini ise 18-25 yaş arası futbolcular oluşturmaktadır.

Kontrol grubu sene içerisinde planlanan futbol teknik ve taktik antrenmanlarını yapmışlardır. Deney grubuna ise futbol teknik ve taktik antrenmanlarına ek olarak haftada 3 gün olmak üzere 8 hafta boyunca core egzersizleri uygulanmıştır. Uygulanan core egzersizleri temel seviye olup, literatürde core kuvveti gelişimini destekleyen hareketlerden seçilmiştir (Suh ve ark., 2019). Kontrol ve deney grubundan 8 hafta yaptırılan egzersiz uygulamasının başlangıcında ve bitişinde olmak üzere toplam iki defa ölçüm alınmıştır. Futbolculardan Bilgilendirilmiş Gönüllü Olur Formu alınmış olup, Niğde Ömer Halisdemir Üniversitesi Girişimsel Olmayan Klinik Araştırmalar Etik Kurulundan 2021/66 nolu protokol kodu Karar no: 2020/69 ile etik kurul raporu alınmıştır.

Tablo 1. Deney grubu Egzersiz protokolü

\begin{tabular}{|c|c|c|c|c|c|c|c|c|}
\hline \multicolumn{9}{|c|}{ Core Egzersiz Planı } \\
\hline Hareketler & 1. Hafta & 2. Hafta & 3. Hafta & 4. Hafta & 5. Hafta & 6. Hafta & 7. Hafta & 8. Hafta \\
\hline Dinlenme(sn) & $0-90 s$ & $0-60 \mathrm{~s}$ & $0-60 s$ & $0-60 s$ & $0-60 \mathrm{~s}$ & $0-60 \mathrm{~s}$ & $0-60 s$ & $0-60 \mathrm{~s}$ \\
\hline Set sayısı & $2-3$ & $2-3$ & $2-3$ & $2-3$ & $2-3$ & $2-3$ & $2-3$ & $2-3$ \\
\hline Tempo & Yavaş & Orta & Orta & Orta & Yüksek & Yüksek & Yüksek & Yüksek \\
\hline $\begin{array}{ll}\text { Side } & \text { Plank } \\
\text { Hold(sn) } & \end{array}$ & $25 \times 2$ & $25 \times 2$ & $30 \times 2$ & $30 \times 2$ & $35 \times 2$ & $35 \times 2$ & $40 \times 2$ & $40 \times 2$ \\
\hline $\begin{array}{ll}\text { Floor } & \text { Bridge } \\
\text { (adet) } & \\
\end{array}$ & $20 \times 2$ & $20 \times 2$ & $25 \times 2$ & $25 \times 2$ & $30 \times 2$ & $30 \times 2$ & $35 \times 2$ & $35 \times 2$ \\
\hline $\begin{array}{l}\text { Hip\&Shoulder } \\
\text { Abduction (adet) }\end{array}$ & $20 \times 2$ & $20 \times 2$ & $25 \times 2$ & $25 \times 2$ & $30 \times 2$ & $30 \times 2$ & $35 \times 2$ & $35 \times 2$ \\
\hline Deadbugs(adet) & $20 \times 2$ & $20 \times 2$ & $25 \times 2$ & $25 \times 2$ & $30 \times 2$ & $30 \times 2$ & $35 \times 2$ & $35 \times 2$ \\
\hline Bird dog(adet) & $20 \times 2$ & $20 \times 2$ & $25 \times 2$ & $25 \times 2$ & $30 \times 2$ & $30 \times 2$ & $35 \times 2$ & $35 \times 2$ \\
\hline Mekik(adet) & $20 \times 2$ & $20 \times 2$ & $25 \times 2$ & $25 \times 2$ & $30 \times 2$ & $30 \times 2$ & $35 \times 2$ & $35 \times 2$ \\
\hline Plank(sn) & $45 \times 2$ & $45 \times 2$ & $50 \times 2$ & $50 \times 2$ & $40 \times 2 \mathrm{~T}$ & $40 \times 2 \mathrm{~T}$ & $50 \times 2 \mathrm{~T}$ & $50 \times 2 \mathrm{~T}$ \\
\hline
\end{tabular}

(Suh ve ark., 2019; Egesoy ve ark., 2018) T; Tek Bacak Havada

Futbolcuların boy uzunlukları stadiometre (Harpenden, Holtain Ltd.) ile BMI ve VYY ve kilo ağırlıkları Tanita marka vücut analizi sistemi (Tanita Corporation, Tokyo, Japan) ile ölçülmüştür.

\section{Verilerin Toplanması}

Dikey Sıçrama: Futbolcuların dikey sıçrama performansı Fotosel bağlantılı mat Smartspeed (Fusion Sport, Australia) aleti ile ölçülmüştür. Futbolcular mat üzerinde ayaklar omuz genişliğinde açık, vücut dizlerden $90^{\circ}$ bükülü ve öne doğru eğik, kollar 
belde sabit şeklide ölçüm yapılmıştır (Reeve ve Tyler, 2013). Test iki kez tekrar edilmiş, en iyi değer cm olarak kaydedilmiştir.

Anaerobik güç; Lewis ölçüm formülüne göre hesaplanmıştır;

- $P=\sqrt{ } 4,9 \times$ Ağırlık $(\mathrm{kg}) \times \sqrt{ } \mathrm{D}(\mathrm{m}) \times(9,8) P$ : Güç (watt), $D=$ Dikey Sıçrama Mesafesi (m) (Ergun ve Baltacı, 2015)

Illinois Çeviklik Testi : Futbolcuların çeviklik performansı Smartspeed (Fusion Sport, Australia) aleti ile ölçülmüştür. Test parkuru hazırlandıktan sonra futbolcu ayakta, başlangıç fotoselinin $1 \mathrm{~m}$ arkasında gerisindedir. Futbolcu istediği zaman koşuya başlamış, gösterilen pisti, başlangıç fotoselinden başlayıp okların takip ettiği yönde hareket edip, ikinci bitiş fotoselinde parkuru tamamlamıştır. Eni 5 metre, boyu 10 metre ve orta bölümdeki konilerin arası 3,30 metredir. Futbolculardan parkuru en iyi seviyede yapılması istenmiştir. En iyi değer sn cinsinden kaydedilmiştir (Hachana ve ark., 2014).

Sürat Testi: Futbolcuların 20 ve 30 metre sürat performansı Smartspeed (Fusion Sport, Australia) aleti ile ölçülmüştür. Başlangıç ve Bitiş fotoselleri arasında 20m'lik düz bir zemin üzerinde test gerçekleştirilmiştir (Weerakkody ve ark., 2021). Test iki kez tekrar edilmiş, en iyi değer sn cinsinden kaydedilmiştir.

Cooper (Aerobik) Testi: Futbolcuların aerobik performansı Cooper testi ile ölçülmüştür. Futbolcular 400 m’lik koşu pistinde 12 dakika boyunca koşmaları, yorulmaları halinde yürümeleri istenmiştir. Toplam mesafe (m cinsinden) kaydedilmiştir.

Maksimum VO2' nin tahmin edilmesinde aşağıdaki formül kullanılmıştır;

- Tahmini VO2 maksimum $\left(\mathrm{ml} \cdot \mathrm{kg}^{-1} \cdot \mathrm{dk}^{-1}\right)=($ kilometreye çevrilen alınan mesafe x 22.351 mesafe)-11.288 (Meredith ve Welk, 2003; Koç ve ark., 2020)

\section{Verilerin analizi}

Futbolcuların yaş, boy, kilo ve ölçüm değişkenlerine tanımlayıcı istatistik analizleri yapılmış, kontrol ve deney gruplarının ön test, son test ölçümlerinin arasındaki farklıı̆ı̆ı belirlenmesinde wilcoxon işaretli sıralar testi, ön test ve son test ölçümlerinin gruplar (kontrol-deney) arasındaki farklılığın belirlenmesinde MannWhitney $U$ testi analizi kullanılmıştır. Çalışmada anlamlılık düzeyi 0,05 olarak kabul edilmiştir. 


\section{Bulgular}

Tablo 2. Futbolcuların betimleyici özelliklerine ait tanımlayıcı istatistikleri

\begin{tabular}{|c|c|c|c|c|c|c|c|c|c|c|c|}
\hline \multirow{2}{*}{ Test / Grup } & \multirow{2}{*}{ Değişken } & \multicolumn{5}{|c|}{ Kontrol } & \multicolumn{5}{|c|}{ Deney } \\
\hline & & $\mathbf{N}$ & $\bar{x}$ & SS & Min. & Mak. & $\mathbf{N}$ & $\bar{x}$ & SS & Min. & Mak. \\
\hline \multirow{3}{*}{ Ön Test } & Yaş (yıl) & & 22,60 & 3,29 & 19,00 & 25,00 & \multirow{3}{*}{15} & 21,60 & 2,29 & 18,00 & 25,00 \\
\hline & Boy (m) & 15 & 1,79 & 0,06 & 1,70 & 1,88 & & 1,82 & 0,06 & 1,70 & 1,90 \\
\hline & Kilo (kg) & & 73,27 & 6,38 & 63,70 & 87,40 & & 76,77 & 6,56 & 60,90 & 87,30 \\
\hline \multirow{3}{*}{ Son Test } & Yaş (yıl) & & 22,60 & 3,29 & 19,00 & 25,00 & \multirow{3}{*}{15} & 21,60 & 2,29 & 18,00 & 25,00 \\
\hline & Boy $(m)$ & 15 & 1,79 & 0,06 & 1,70 & 1,88 & & 1,82 & 0,06 & 1,70 & 1,90 \\
\hline & Kilo (kg) & & 73,17 & 6,51 & 63,20 & 87,20 & & 76,43 & 6,69 & 60,10 & 87,00 \\
\hline
\end{tabular}

Tablo 3. Kontrol ve deney grubu futbolcuların ön test ve son test ölçüm sonuçlarının karşılaştırılması

\begin{tabular}{|c|c|c|c|c|c|c|c|}
\hline Grup & Değişken & $\begin{array}{l}\text { Eşli } \\
\text { Grup }\end{array}$ & $\mathbf{N}$ & $\bar{x}$ & SS & $\mathbf{z}$ & $\mathbf{P}$ \\
\hline \multirow{16}{*}{ Kontrol } & \multirow{2}{*}{ Cooper (ml/kg/dk) } & Ön Test & 15 & 41,75 & 5,55 & \multirow{2}{*}{$-2,71$} & \multirow{2}{*}{$0,01^{x}$} \\
\hline & & Son Test & 15 & 43,17 & 4,37 & & \\
\hline & \multirow{2}{*}{20 m Sprint (sn) } & Ön Test & 15 & 3,08 & 0,12 & \multirow{2}{*}{$-1,08$} & \multirow{2}{*}{0,28} \\
\hline & & Son Test & 15 & 3,07 & 0,2 & & \\
\hline & \multirow{2}{*}{30 m Sprint (sn) } & Ön Test & 15 & 4,33 & 0,17 & \multirow{2}{*}{$-0,175$} & \multirow{2}{*}{0,86} \\
\hline & & Son Test & 15 & 4,28 & 0,28 & & \\
\hline & \multirow{2}{*}{$\begin{array}{l}\text { Dikey Sıçrama } \\
\text { Mesafesi }(\mathrm{cm})\end{array}$} & Ön Test & 15 & 42,65 & 1,3 & \multirow{2}{*}{$-0,707$} & \multirow{2}{*}{0,48} \\
\hline & & Son Test & 15 & 42,78 & 1,73 & & \\
\hline & \multirow{2}{*}{ Çeviklik (sn) } & Ön Test & 15 & 15,86 & 0,26 & \multirow{2}{*}{$-0,8$} & \multirow{2}{*}{0,42} \\
\hline & & Son Test & 15 & 15,75 & 0,42 & & \\
\hline & \multirow{2}{*}{$\operatorname{BMI}\left(\mathrm{kg} / \mathrm{m}^{2}\right)$} & Ön Test & 15 & 22,89 & 1,65 & \multirow{2}{*}{$-1,545$} & \multirow{2}{*}{0,12} \\
\hline & & Son Test & 15 & 22,68 & 1,65 & & \\
\hline & \multirow{2}{*}{ VYY (\%) } & Ön Test & 15 & 13,38 & 3,44 & \multirow{2}{*}{$-3,183$} & \multirow{2}{*}{$0,00^{\prime}$} \\
\hline & & Son Test & 15 & 11,8 & 2,86 & & \\
\hline & \multirow{2}{*}{$\begin{array}{l}\text { Anaerobik Güç } \\
\text { (watt) }\end{array}$} & Ön Test & 15 & 1059,46 & 98,53 & \multirow{2}{*}{$-0,114$} & \multirow{2}{*}{0,91} \\
\hline & & Son Test & 15 & 1059,62 & 103,02 & & \\
\hline \multirow{16}{*}{ Deney } & \multirow{2}{*}{ Cooper (ml/kg/dk) } & Ön Test & 15 & 41,29 & 6,6 & \multirow{2}{*}{$-2,601$} & \multirow{2}{*}{$0,01^{*}$} \\
\hline & & Son Test & 15 & 45,08 & 4,84 & & \\
\hline & 20 m Snrint (sn) & Ön Test & 15 & 3,03 & 0,12 & -2197 & $003 *$ \\
\hline & LU III spritil (SII) & Son Test & 15 & 2,96 & 0,34 & $-2,191$ & $0,0 s^{2}$ \\
\hline & $20 \mathrm{~m}$ Cnvint (sn) & Ön Test & 15 & 4,25 & 0,16 & 0100 & $06 ?$ \\
\hline & su m spmint (Sn) & Son Test & 15 & 4,21 & 0,24 & $-0,489$ & 0,03 \\
\hline & Dikey Sıçrama & Ön Test & 15 & 44,07 & 0,97 & -0341 & $000 *$ * \\
\hline & Mesafesi $(\mathrm{cm})$ & Son Test & 15 & 45,33 & 0,92 & $-0,341$ & $0,00^{n}$ \\
\hline & & Ön Test & 15 & 15,85 & 0,84 & & \\
\hline & Çeviklik (sn) & Son Test & 15 & 15,5 & 0,62 & $-0,306$ & $0,00^{*}$ \\
\hline & $\mathrm{RMMl}\left(\mathrm{kg} / \mathrm{m}^{2}\right)$ & Ön Test & 15 & 22,91 & 1,52 & & 021 \\
\hline & BIVII (Kg/m) & Son Test & 15 & 22,77 & 1,43 & 45 & $0, \angle 1$ \\
\hline & (MY (O) & Ön Test & 15 & 11,15 & 3,98 & $267 ?$ & \\
\hline & VYY (\%) & Son Test & 15 & 10,14 & 3,46 & $-\angle, 6 / 2$ & $0,01^{\wedge}$ \\
\hline & Anaerobik Güç & Ön Test & 15 & 1128,35 & 100,31 & & \\
\hline & (watt) & Son Test & 15 & 1139,54 & 105,27 & $-2,442$ & $0,02^{*}$ \\
\hline
\end{tabular}

${ }^{*} p<0,05$; VYY: Vücut Yağ Yüzdesi; BMI: Beden Kitle İndeksi 
Tablo 3 incelendiğinde kontrol grubu futbolcuların Cooper testi ve vücut yağ yüzdesi ön test ve son test sonuçlarının karşılaştııımasında anlamlı fark olduğunu farkın son test lehine olduğu tespit edilmiştir. $20 \mathrm{~m}$ sprint, $30 \mathrm{~m}$ sprint, dikey sıçrama, çeviklik BMI, VYY ve anaerobik güç değişkenlerinde fark saptanmamıştır. Deney grubu futbolcuların ise cooper, $20 \mathrm{~m}$ sprint, dikey sıçrama, çeviklik, VYY ve anaerobik güç ön test ve son test sonuçlarının karşılaştııımasında anlamlı fark olduğunu farkın son test lehine olduğu tespit edilmiştir. $30 \mathrm{~m}$ sprint ve BMI değişkenlerinin ön test ve son test sonuçlarının karşılaştırımasında anlamlı fark olmamasına rağmen son test ortalamalarının daha iyi olduğu tespit edilmiştir.

Tablo 4. Kontrol ve deney gruplarının ön test ve son test ölçüm sonuçlarının karşılaştırılması

\begin{tabular}{|c|c|c|c|c|c|c|c|}
\hline Test Grubu & Değişken & Grup & $\mathbf{N}$ & & SS & $\mathbf{z}$ & $\mathbf{P}$ \\
\hline \multirow{16}{*}{ Ön Test } & \multirow{2}{*}{ Cooper (ml/kg/dk) } & Kontrol & 15 & 41,75 & 5,55 & \multirow{2}{*}{$-0,146$} & \multirow{2}{*}{0,88} \\
\hline & & Deney & 15 & 41,29 & 6,6 & & \\
\hline & \multirow{2}{*}{20 m Sprint (sn) } & Kontrol & 15 & 3,08 & 0,12 & \multirow{2}{*}{$-0,914$} & \multirow{2}{*}{0,36} \\
\hline & & Deney & 15 & 3,03 & 0,12 & & \\
\hline & \multirow{2}{*}{30 m Sprint (sn) } & Kontrol & 15 & 4,33 & 0,17 & \multirow{2}{*}{0,996} & \multirow{2}{*}{0,32} \\
\hline & & Deney & 15 & 4,25 & 0,16 & & \\
\hline & \multirow{2}{*}{ Dikey Sıçrama Mesafesi (cm) } & Kontrol & 15 & 42,65 & 1,3 & \multirow{2}{*}{$-3,216$} & \multirow[b]{2}{*}{$0,00^{*}$} \\
\hline & & Deney & 15 & 44,07 & 0,97 & & \\
\hline & \multirow{2}{*}{ Çeviklik (sn) } & Kontrol & 15 & 15,86 & 0,26 & \multirow{2}{*}{$-0,747$} & \multirow{2}{*}{0,46} \\
\hline & & Deney & 15 & 15,85 & 0,84 & & \\
\hline & \multirow{2}{*}{ BMI $\left(\mathrm{kg} / \mathrm{m}^{2}\right)$} & Kontrol & 15 & 22,89 & 1,65 & \multirow{2}{*}{$-0,395$} & \multirow{2}{*}{0,69} \\
\hline & & Deney & 15 & 22,91 & 1,52 & & \\
\hline & \multirow{2}{*}{ VYY (\%) } & Kontrol & 15 & 13,38 & 3,44 & \multirow{2}{*}{$-1,203$} & \multirow{2}{*}{0,23} \\
\hline & & Deney & 15 & 10,14 & 3,98 & & \\
\hline & \multirow{2}{*}{ Anaerobik Güç (watt) } & Kontrol & 15 & 1059,46 & 98,53 & \multirow{2}{*}{$-2,095$} & \multirow{2}{*}{$0,04^{*}$} \\
\hline & & Deney & 15 & 1128,35 & 100,31 & & \\
\hline \multirow{16}{*}{ Son Test } & \multirow{2}{*}{ Cooper (ml/kg/dk) } & Kontrol & 15 & 43,17 & 4,37 & \multirow{2}{*}{$-1,187$} & \multirow{2}{*}{0,24} \\
\hline & & Deney & 15 & 45,08 & 4,84 & & \\
\hline & 20 m Sprint (sn) & Kontrol & 15 & 3,07 & 0,2 & 139 & 0.17 \\
\hline & Lu mi sprml (sil) & Deney & 15 & 2,96 & 0,34 & 1,39 & 0,16 \\
\hline & & Kontrol & 15 & 4,28 & 0,28 & & 011 \\
\hline & 30 m Sprınt (sn) & Deney & 15 & 4,21 & 0,24 & $-0,167$ & 0,44 \\
\hline & Dikev Sicrama Mesafesi (cm) & Kontrol & 15 & 42,78 & 1,73 & -3464 & $0 \cap 0 *$ \\
\hline & LIkey sıçrama IVIesatesI (cm) & Deney & 15 & 45,33 & 0,92 & $-3,464$ & $0,00^{x}$ \\
\hline & & Kontrol & 15 & 15,75 & 0,42 & -197 & $005 *$ \\
\hline & ÇeVIKIIK (Sn) & Deney & 15 & 15,5 & 0,62 & $-1,91$ & $0,05^{\wedge}$ \\
\hline & $\mathrm{BMI}\left(\mathrm{kg} / \mathrm{m}^{2}\right)$ & Kontrol & 15 & 22,68 & 1,65 & $-0,436$ & 066 \\
\hline & BIVII (Kg/m) & Deney & 15 & 22,77 & 1,43 & $-0,436$ & 0,66 \\
\hline & VYY (0) & Kontrol & 15 & 11,8 & 2,86 & 60 & 017 \\
\hline & VYY (\%) & Deney & 15 & 10,14 & 3,46 & $-1,309$ & 0,16 \\
\hline & G & Kontrol & 15 & 1059,62 & 103,02 & & $2 *$ \\
\hline & $1001 K$ Gü̧ & Deney & 15 & 1139,54 & 105,27 & $-2,110$ & 0,0 \\
\hline
\end{tabular}

${ }^{\star} p<0,05$; VYY: Vücut Yağ Yüzdesi; BMI: Beden Kitle İndeksi 
İri, R., Öztekin, B., ve Şengür, E. (2021). Futbolculara Uygulanan Core Egzersizlerinin Bazı Motorik Özellikler Üzerine Etkisi. Gaziantep Üniversitesi Spor Bilimleri Dergisi, 6(3), 298-310.

Tablo 4 incelendiğinde ön test sonuçlarının karşılaştırılmasında kontrol ve deney gruplarının cooper, 20 m sprint, 30 m sprint, çeviklik BMI, VYY değişkenlerinde fark saptanmamıştır. Dikey sıçrama ve anaerobik güç değişkeninde gruplar arası karşılaştırmada fark olduğu, farkın deney grubu lehine olduğu tespit edilmiştir. Son test sonuçlarının karşılaştırılmasında kontrol ve deney gruplarının cooper, $20 \mathrm{~m}$ sprint, 30 m sprint, BMI, VYY değişenlerinde fark saptanmamıştır. Dikey sıçrama, anaerobik güç ve çeviklik değişkenlerinde gruplar arası karşılaştırılmasında fark olduğu, farkın deney grubu lehine olduğu tespit edilmiştir.

\section{Tartışma ve Sonuç}

Core egzersizleri, kas gücünün artmasına bağlı olarak sakatlıkların önlenmesi, çeşitli kas sisteminde koordinasyonun geliştirmesiyle beraber futbol branşı için önemli olan çabukluk, sürat, denge, uzun atlama gibi motorik özellikler gelişiminde etkisi olduğu bilinmektedir (Prieske ve ark., 2015)

Yapılan çalışmada 8 haftalık süreç içerisinde hem kontrol grubunun hem de deney grubunun kilo ortalamasının, BMI ortalamasının ve VYY ortalamasının düştüğü tespit edilmiştir. Bu durumun oluşmasında yaptırılan hem teknik taktik ve kondisyon antrenmanlarının hem de core egzersizlerinin etkisi olduğu düşünülmektedir. Arslan ve ark., (2021) futbolcular üzerine yaptıkları çalışmada core egzersizlerinin BMI ve VYY ortalamasını düşürdüğünü belirtmişlerdir. Başka bir çalışmada Özgül (2019) futbolcular üzerine yaptığı çalışmada core ve pliometrik egzersizlerin BMI ve VYY ortalamasını düşürdüğünü belirtmiştir. Doğan ve ark., (2016) futbolcular üzerine yaptıkları çalışmada core egzersizlerinin BMI ve VYY ortalamasını düşürdüğünü belirtmişlerdir. Core egzersizleri sonrasında BMI ve VYY ortalamalarının düşmesinde kas kütlesinin artmasından kaynaklandığı düşünülmektedir (Aydın, 2019). Literatürdeki çalışmalar bulgularımızı destekler niteliktedir.

Yapılan çalışmada kontrol grubu futbolcuların ön test ve son test sonuçlarının karşılaştırılmasında cooper testi ve VYY'nde anlamlı fark tespit edilirken, deney grubu futbolcuların ön test ve son test sonuçlarının karşılaştırılmasında cooper, 20 m sprint, dikey sıçrama, çeviklik, VYY ve anaerobik güç değişkenlerinde anlamlı fark tespit edilmiştir. Kontrol ve deney grubu futbolcuların ön test sonuçlarının karşılaştırılmasında dikey sıçrama ve anaerobik güç değişkeninde anlamlı fark tespit edilirken, kontrol ve deney grubu futbolcuların son test karşılaştırmasında ön testten dikey sıçrama, anaerobik güce ek olarak çeviklik değişkeninde anlamlı fark olduğu 
tespit edilmiştir. Bu farklıı̆ın oluşmasında futbolculara uygulanan teknik taktik ve kondisyon antrenmanlarına ek olarak yaptırılan core egzersizlerinin, kasta motor ünite aktivasyonunun artmasına bağlı olarak kas hipertrofisinin oluşması, gelişen kas sistemi ile üst bölge ve alt bölge arasında köprü vazifesi yaparak core bölgesindeki kas gücünü koordineli şekilde kullanmaya olanak sağlayarak performansa etki ettiği düşünülmektedir.

Literatürde futbolcular üzerine yapılan çalışmalar incelendiğinde Arslan ve ark., (2021) yaptığı çalışmada kısa alan oyunlarına ek olarak core egzersizlerinin eklemesinin, futbolcuların performansına etkisini incelemişlerdir. Çalışma sonucunda 6 haftalık core egzersizlerinin 20 m sürat performansını geliştirdiğini, antrenmanlara ek core egzersizlerinin eklemesinin fiziksel performansa etkisinin olumlu olacağını belirtmişlerdir. Başka bir çalışmada Turna (2020) futbolcular üzerine yaptığı çalışmada 6 haftalık core egzersizlerinin seçilmiş biyomotor özellikler üzerine etkini incelemiştir. Çalışma sonucunda uygulanan core egzersizlerinin $30 \mathrm{~m}$ sürat ve dikey sıçrama performansını geliştirdiğini, core egzersizlerinin temel biyomotor becerileri geliştirmede etkili bir yöntem olduğunu, futbol yönetici ve antrenörlerin yıllık antrenman programlarına ek olarak, bu egzersizlerinin eklemesinin olumlu etkileri olacağını belirtmişlerdir.

Özgül (2019) futbolcular üzerine yaptığı çalışmada 8 haftalık core ve pliometrik antrenmanların bazı motorik özellikler üzerine etkisini incelemiştir. Çalışma sonucunda uygulanan core ve pliometrik egzersizlerin, $30 \mathrm{~m}$ sürat, çeviklik ve dikey sıçrama performansını geliştirdiğini, uygulanan antrenman programının motor performans ve beden kompozisyonunu olumlu şekilde etkilediğini belirtmişlerdir. Başka bir çalışmada Dikici (2018) yaptığı çalışmada, core egzersiz modelinin öğrencilerin fizyolojik parametrelerine etkisini incelemiştir. Çalışma sonucunda 8 haftalık core egzersizlerinin, $30 \mathrm{~m}$ sürat, çeviklik ve anaerobik performansını geliştirdiğini, uygulanacak farkı core egzersiz programlarının motor performans üzerine etki edeceğini belirtmiş̧ir. Alpşahin (2018) yaptığı çalışmada futbolcular uygulanan 8 haftalık core egzersizlerinin denge ve futbol becerilerine etkisini incelemiştir. Çalışma sonucunda 8 haftalık core egzersizlerinin sürat ve çeviklik performansını geliştirdiğini, futbolcuların motorik özelliklerinin futbol becerilerine etkisini belirlenmesinde uygulanan antrenman şekilleri ve oyuncuların teknik becerilerinin dikkate alınması gerektiğini belirtmiştir. Başka bir çalışmada Vigneshwaran (2017) yaptığı çalışmada core egzersizlerinin futbolcuların sürat 
performansı üzerine etkisini incelemiştir. Çalışma sonucunda 8 haftalık core egzersizlerinin sürat performansını geliştirdiğini belirtmiştir. Doğan ve ark., (2016) futbolcular üzerine yaptığı çalışmada 8 haftalık core egzersizlerinin bazı fiziksel ve fizyolojik parametreler üzerine etkisini incelemişlerdir. Çalışma sonucunda core egzersizlerinin, 20 m sürat, dikey sıçrama ve aerobik performansını geliştirdiğini, bu egzersizlerin antrenmanlara ek olarak uygulanmasının faydalı olacağını belirtmişlerdir. Dilber ve ark., (2016) yaptığı çalışmada futbolcularda core egzersizlerinin performansla ilgili fiziksel değişkenleri üzerine etkisini incelemişlerdir. Çalışma sonucunda 8 haftalık core egzersizlerinin çeviklik, dikey sıçrama ve anaerobik performansı geliştirdiğini, bir kuvvet egzersiz türü olması sebebiyle performans amaçlı kullanılabileceğini belirtmişlerdir.

Bayrakdar (2020) futbolcular üzerine yaptığı çalışmada statik ve dinamik core egzersizlerinin futbolcular üzerine etkisini incelemiştir. Çalışma sonucunda uygulanan 9 haftalık core egzersizlerinin çeviklik, dikey sıçrama performansını geliştirdiğini, koruyucu ve fonksiyonel kapasiteye olumlu etkilerinden dolayı core egzersizlerinin futbol antrenman programlarına dahil edilmesinin yararlı olacağını belirtmiştir. Prieske ve ark., (2015) yaptığı çalışmada elit futbolcularda core egzersizlerinin nöromüsküler ve atletik performans üzerine etkisini incelemişlerdir. Çalışma sonucunda 9 haftalık core egzersizlerinin 10-20 m sürat performansını geliştirdiğini, atletik performansın geliştirilmesinde antrenman uyaran çeşitliliğini de arttırdığını belirtmişlerdir. Baş (2018) yaptığı çalışmada futbolculara uygulanan core egzersizlerinin seçili motor parametrelerine etkisini incelemiştir. Çalışma sonucunda 10 haftalık core egzersizlerinin $20 \mathrm{~m}$ sürat ve dikey sıçrama performansını geliştirdiğini, düzenli olarak yapılan core egzersizlerinin temel motor gelişimine olumlu yönde katkı sağlayacağını belirtmiştir. Başka bir çalışmada Boyacı ve Afyon (2017) yaptığı çalışmada core egzersizlerinin fiziksel performansa etkisini incelemişlerdir. Çalışma sonucunda 12 haftalık core egzersizlerinin $20 \mathrm{~m}$ sürat ve çeviklik performansını geliştirdiğini, futbolcuların fiziksel performansının geliştirilmesi için core egzersizlerini önermektedir. Afyon (2014) yaptığı çalışmada core egzersizlerinin futbolcular üzerine etkisini incelemiştir. Çalışma sonucunda 12 haftalık core egzersizlerinin uzun atlama, mekik, şınav, denge, şınav ve 20 m sürat performansını geliştirdiğini, majör ve minör kas gruplarının gelişmesiyle motorik ve fiziksel gelişimlere katkısı olduğunu belirtmiştir. Imai ve ark., (2014) yaptığı çalışmada iki tip gövdeyi kuvvetlendirme egzersizlerinin futbolcularda atletik performans üzerine etkisini incelemişlerdir. 
Çalışma sonucunda 12 haftalık core egzersizlerinin çeviklik, dikey sıçrama ve aerobik performansı geliştirdiğini belirtmişlerdir. Hareketin merkezi ve kinetik zincirin odağı olan core bölgesi tarafından core kuvvetinin, dengesinin ve hareketinin kontrolü ile alt ve üst ekstremite fonksiyonu en üst seviyeye çıkarılarak core kuvvet artışı ile futbolcuların koşma, yön değiştirme, dikey sıçrama, hareketlerde beceri, koordinasyon, verimlilik, çabukluk, sürat gibi motorik yeteneklerinin gelişmesinde katkısı olduğu düşünülmektedir (Eriş, 2018; Lacono ve ark., 2014). Sato ve Mokha (2009) yaptığı çalışmada core egzersizlerinin koşucularda koşu kinetiğini ve alt ekstremite stabilitesi ve $5000 \mathrm{~m}$ performansı üzerine etkisini incelemişleridir. Çalışma sonucunda 6 haftalık core egzersizlerinin aerobik performansı geliştirdiğini belirtmişlerdir. Core egzersizleri sonucunda solunum kaslarının güçlenmesinin aerobik performansın gelişmesinde etkili olduğu düşünülmektedir (Young-Bae ve ark., 2021; Pişkin ve ark., 2020; Mustafaoglu ve ark., 2019). Literatürdeki çalışmalar incelendiğinde core egzersizlerinin sürat, çeviklik, dikey sıçrama aerobik ve anaerobik performans karşılaştııımasında bulgularımızı destekler niteliktedir. Buna ek olarak core egzersizlerinin sportif açıdan denge, uzun atlama ve branşa özgü temel teknik özelliklere de katkısı olduğu görülmüştür.

Sonuç olarak, sezon öncesi hazırlık döneminde uygulanan temel seviye core egzersizlerinin temel motorik özellikleri geliştirdiği tespit edilmiştir. Futbolcular üzerinde elde edilen sonuçlar neticesinde, çeşitli branşlarda uygulanacak core egzersizlerinin temel motorik özelliklerin geliştirilmesinde katkısının olacağı düşünülmektedir.

\section{Kaynaklar}

Afyon, Y.A. (2014). Effect of core training on 16 year-old soccer players. Educational Research and Reviews, 9(23), 1275- 1279.

Alpşahin, İ. (2018). Futbolculara uygulanan sekiz haftalık core antrenmanın denge ve futbol becerilerine etkileri. Yüksek Lisans Tezi. Sağlık Bilimleri Enstitüsü. Gaziantep Üniversitesi. Gaziantep.

Arslan, E, Soylu, Y, Clemente, F.M. et al. (2021). Short-term effects of on-field combined core strength and small-sided games training on physical performance in young soccer players. Biology of Sport, 38(4), 609-616. 
Aslan, A.K., Erkmen, N., Aktaş, S. ve Güven, F. (2018). Postural control and functional performance after core training in young soccer players. Movement, Health \& Exercise, 7(2), 23-38.

Aydın, A.S. (2019). 13-15 yaş Badminton sporcularına uygulanan sekiz haftalık "core" antrenmanların denge, kas kuvveti, sürat ve çeviklik performansları üzerine etkisinin incelenmesi. Yüksek Lisans Tezi. Sağlık Bilimleri Enstitüsü. İstanbul Gelişim Üniversitesi. İstanbul

Baş, M. (2018). 11-13 yaş grubu futbolculara uygulanan 10 haftalık core antrenmanın seçili motor parametrelere etkisinin değerlendirilmesi. Yüksek Lisans Tezi. Sağlık Bilimleri Enstitüsü. İstanbul Gelişim Üniversitesi. İstanbul.

Bayrakdar, A., Boz, H.K. ve Işıldar, Ö. (2020). The investigation of the effect of static and dynamic core training on performance on football players. Turkish Journal of Sport and Exercise, 22(1), 87-95.

Boyacı, A. ve Afyon, Y.A. (2017). The effect the core training to physical performans in children. Journal of Education and Practice, 8(33), 81-88.

Dikici, S. (2018). Spor yapan ortaöğretim çağındaki öğrencilerde core antrenman modelinin öğrencilerin fizyolojik parametrelerine etkisi. Yüksek Lisans Tezi. Sağlık Bilimleri Enstitüsü. Kahramanmaraş Sütçü İmam Üniversitesi. Kahramanmaraş.

Dilber, A.O., Lağap, B., Akyüz, Ö., Çoban, C., Akyüz, M., Taş, M., Akyüz, F. ve Özkan, A. (2016). Erkek futbolcularda 8 haftalık kor antrenmanının performansla ilgili fiziksel uygunluk değişkenleri üzerine etkisi. CBÜ Beden Eğitimi ve Spor Bilimleri Dergisi, 11(2), 77-82.

Doğan, G., Mendeş, B., Akcan, F. ve Tepe, A. (2016). Futbolculara uygulanan sekiz haftalık core antrenmanın bazı fiziksel ve fizyolojik parametreler üzerine etkisi. Beden Eğitimi ve Spor Bilimleri Dergisi, 10(1), 1-12.

Egesoy, H., Alptekin, A. ve Yapıcı, A. (2018). Sporda kor egzersizler. International Journal of Contemporary Educational Studies (IntJCES), 4(1), 10-21.

Ergun, N. ve Baltacı, G. (2015). Spor yaralanmalarında fizyoterapi ve rehabilitasyon prensipleri. Ankara: Pelikan Yayıncılık.

Eriş, F. (2018). Kadın badminton sporcularında 12 haftalık core kuvveti egzersizlerinin bazı antropometrik değerler statik denge ve core kuvveti üzerine etkisinin araştırılması. Doktora Tezi. Sağlık Bilimleri Enstitüsü. Van Yüzüncü Yıl Üniversitesi. Van, 
Gönener, A., Demirci, D., Yılmaz, O., Özer, B. ve Yılmaz, O. (2017). 13-15 yaş grubu erkek yüzücülerde 8 haftalık core antrenmanının sırt üstü stili $100 \mathrm{~m}$ performansına etkisi. Sportif Bakış: Spor ve Eğitim Bilimleri Der., SI(1), 29-37.

Hachana, Y., Chaabène, H., Ben Rajeb, G., Khlifa, R., Aouadi, R., Chamari, K. and Gabbett, T. J. (2014). Validity and reliability of new agility test among elite and subelite under 14-soccer players. PloS One, 9(4), https://doi.org/10.1371/journal.pone.0095773

Lacono, A.D., Martone, D., Alfieri, A., Ayalon, M. and Buono, P. (2014). Core stability training program (cstp) effects on static and dynamic balance abilities. Gazzetta Medica Italiana Archivio per le Scienze Mediche, 173(4), 197-206.

Imai, A., Kaneoka, K., Okubo, Y. and Shiraki, H. (2014). Effects of two type of trunk exercises on balance and athletic performance in youth soccer players. The International Journal of Sports Physical Therapy, 9(1), 47-57.

Jones, J. (2013). Core Training Concepts. NASM.

Koç, M., Dongaz, Ö.İ., Bayar, B., Bayar, K. (2020). Üniversite öğrencilerinden oluşan kız ve erkek voleybol oyuncularının bazı fiziksel uygunluk özelliklerinin belirlenmesi ve birbiriyle karşılaştııılması. Karya Journal of Health Science, 1(1), 15-18.

Meckel, Y., Machnai, O. and Eliakim, A. (2009). Relationship among repeated sprint tests, aerobic fitness, and anaerobic fitness in elite adolescent soccer players. Journal of Strength and Conditioning Research, 23(1), 163-169.

Meredith, M.D. and Welk, G. (2003). Fitnessgram: Test administration manual: Human Kinetics Publishers.

Mills, A. (2016). Futbol. İstanbul: Caretta Çocuk.

Mustafaoglu, R., Demir, R., Demirci, A.C. ve Yiğit, Z. (2019). Effects of core stabilization exercises on pulmonary function, respiratory muscle strength, and functional capacity in adolescents with substance use disorder: Randomized controlled trial. Pediatric Pulmonology, 57(7), 1002- 1011.

Özgül, A.B. (2019). 17 ve 19 yaş grubu futbolcularda uygulanan core ve pliometrik antrenmanların bazı motorik özelliklere etkisinin incelenmesi. Yüksek Lisans Tezi. Sağlık Bilimleri Enstitüsü. İstanbul Gelişim Üniversitesi. İstanbul.

Pişkin, N., Şengür, E., Öztekin, B. ve Hazar, S. (2020). Sekiz haftalık kuvvet antrenmanlarının solunum parametreleri üzerine etkisinin incelenmesi. Sivas Cumhuriyet Üniversitesi Spor Bilimleri Dergisi,1(3), 107-118. 
Prieske, O., Muehlbauer, T., Borde, R., Gube, M., Bruhn, S., Behm, DG. Granacher, U. (2015). Neuromuscular and athletic performance following core strength training in elite youth soccer: Role of instability. Scandinavian Journal of Medicine \& Science in Sports, 26: 48-56. doi: 10.1111/sms.12403.

Reeve, TC. and Tyler, C.J. (2013). The validity of the smartjump contact mat. Journal of Strength Conditioning Research, 27(6), 1597-1601.

Sato, K. and Mokha, M. (2009). Does core strength training influence running kinetics, lower-extremity stability, and 5000-M performance in runners? Journal of Strength Conditioning Research, 23(1), 133-140.

Stephenson, J. and Swank, A.M. (2004). Core training: Designing a program for anyone. National Strength and Conditioning Association, 26(6), 34-37.

Suh, J.H., Kim, H., Jung, G.P., Ko, J.Y. and Ryu, J.S. (2019). The effect of lumbar stabilization and walking exercises on chronic low back pain: A randomized controlled trial. Medicine, 98(26). doi: 10.1097/MD.0000000000016173.

Sun, X., Gak, Q., Dou, H. and Tang, S. (2016). Which is better in the rehabilitation of stroke patients, core stability exercises or conventional exercises? Journal of Physical Therapy Science, 28(4), 1131-1133.

Şatıroğlu, S. Arslan, E. ve Atak, M. (2013). 'Core antrenman, etkisi ve çalışma örnekleri' 5.Antrenman Bilimi Kongresi.

Turna, B. (2020). the effects of 6-week core training on selected biomotor abilities in soccer players. Journal of Education and Learning, 9(1), 99-109.

Vigneshwaran, G. (2017). Impact of core training on speed among soccer players. IJARIIE-ISSN(O). 3 (3), 4192- 4194.

Weerakkody, N.S., Taylor, C.J., Bulmer, C.L., Hamilton, D.B., Gloury, J., O'Brien, N.J., Saunders, J.H., Harvey, S. and Patterson, T.A. (2021). The effect of mental fatigue on the performance of Australian football specific skills amongst amateur athletes. Journal of Science and Medicine in Sport, 24(6), 592-596.

Yılmaz, S.D. (2021). Core Egzersizlerinin Sporsal Performansa Etkisi: Tekvando Örneği Mini Derleme. Türkiye Klinikleri Spor Bilimleri Dergisi. 13(1), 174-182.

Young-Bae E., Kyung-Tae Y., Yun-Hwan L. and Ho-Seong L. (2021). Effects of Core Stability Exercise on Strength, Activation of Trunk Muscles and Pulmonary Function in a Guillain-Barre Syndrome Patient: Case Report. Journal of the Korean Society of Physical Medicine, 16(1), 111-121. 